\title{
Definindo a construção de um painel de indicadores de desempenho para as IFES - Instituições Federais de Ensino Superior Uma construção usando Grounded Theory
}

\section{Constructing a perfomance indicator panel to Federal Higher Education Institutions building using Grounded Theory}

\author{
Paulo Henrique Santini ${ }^{1}$, José Gilson de Almeida Teixeira Filho ${ }^{2}$ \\ ${ }^{1}$ Instituto Federal de Santa Catarina, Universidade Federal \\ de Pernambuco - cidadaosantini@gmail.com \\ ${ }^{2}$ Universidade Federal de Pernambuco - jgatf@cin.ufpe.br
}

\begin{tabular}{|c|c|}
\hline INFORMAÇÕES & RESUMO \\
\hline $\begin{array}{l}\text { Palavras-chave: } \\
\text { Inteligência de Negócio } \\
\text { (B.I.); } \\
\text { Planejamento Estratégico; } \\
\text { Indicadores de } \\
\text { Desempenho; } \\
\text { Sistemas de Suporte à } \\
\text { Tomada de Decisões; } \\
\text { Grounded Theory. }\end{array}$ & $\begin{array}{l}\text { Neste trabalho são apresentados os resultados do estudo destinado a } \\
\text { determinar e testar um procedimento metodológico que visa obter um } \\
\text { conjunto de indicadores de desempenho, os quais poderiam ser utilizados } \\
\text { pelas IFES - Instituições Federais de Ensino Superior, públicas brasileiras, } \\
\text { notadamente, os Institutos Federais e as Universidades Federais brasileiras. } \\
\text { Estes indicadores poderão ser utilizados durante a elaboração/revisão do } \\
\text { planejamento estratégico institucional (PEI) e/ou planejamento estratégico } \\
\text { de SI/TI (PETI) com objetivo de facilitar a mensuração do atingimento das } \\
\text { metas estratégicas, além de uma interpretação mais precisa do contexto em que } \\
\text { se inserem. Estes indicadores, se utilizados em ferramentas computacionais, } \\
\text { podem apoiar as decisões dos gestores de forma mais objetiva, atualizada e } \\
\text { precisa. O estudo procurou identificar e validar um método para elaboração } \\
\text { deste painel aplicando Grounded Theory em uma amostra dos documentos de } \\
\text { planejamento institucional das IFES, para num trabalho futuro utilizá-lo no } \\
\text { conjunto completo dos documentos de planejamento das mesmas. }\end{array}$ \\
\hline INFORMATION & ABSTRACT \\
\hline $\begin{array}{l}\text { Keywords: } \\
\text { Business Intelligence } \\
\text { (B.I.); } \\
\text { Strategic planning; } \\
\text { Performance indicators; } \\
\text { Support Systems for } \\
\text { Decision Making; } \\
\text { Grounded Theory. }\end{array}$ & $\begin{array}{l}\text { This work presents the results of the study aimed at determining and testing a } \\
\text { methodological procedure that aims to obtain a set of performance indicators, } \\
\text { which could be used by IFES - Federal Institutions of Higher Education, } \\
\text { Brazilian public, notably the Federal Institutes and the Brazilian Federal } \\
\text { Universities. These indicators can be used during the elaboration / review } \\
\text { of institutional strategic planning (PEI) and / or strategic planning of IS / IT } \\
\text { (PETI) in order to facilitate the measurement of the achievement of strategic } \\
\text { goals, in addition to a more accurate interpretation of the context in that fall } \\
\text { within. These indicators, if used in computational tools, can support managers } \\
\text { decisions in a more objective, updated and accurate way. The study sought to } \\
\text { identify and validate a method for the elaboration of this panel by applying } \\
\text { Grounded Theory in a sample of the IFES institutional planning documents, } \\
\text { so that in a future work, it can be used in the complete set of IFES planning } \\
\text { documents. }\end{array}$ \\
\hline
\end{tabular}




\section{INTRODUÇÃO}

As Instituições Federais de Ensino Superior estão situadas em um contexto onde existem muitas dificuldades para gerenciar seus recursos e avaliar os resultados de suas ações dentro de um planejamento estratégico elaborado.

Há muitos motivos para afirmar que a informação se tornou fundamental e vital para o bom andamento da gestão. Dentre eles vale citar: a necessidade de viver em um ambiente de modificações aceleradas como o dos últimos anos; a necessidade de obtenção de informações sobre a sua realidade de atuação; o necessário acompanhamento e controle de custos e investimentos previstos e realizados; o embasamento e sustentação dentro do processo de tomada de decisões; a necessidade de perceber comportamentos e identificar suas causas e consequências; a identificação de tendências e antecipação de situações; e por inúmeras outras razões largamente conhecidas.

Com esta compreensão, e identificando estas necessidades, o presente trabalho deseja construir e testar um método para preencher as lacunas existentes na gestão das IFES com a identificação das mínimas informações e conhecimentos requisitados para a existência de um sistema de tomada de decisões coerente com os seus objetivos estratégicos.

Tendo o domínio dos seus objetivos estratégicos, as organizações de qualquer tipo precisam acompanhar a execução das atividades traçadas para atingir estes objetivos. A literatura apresenta de forma muito farta, a necessidade de utilizar indicadores de desempenho para medir os resultados destas ações, além de suportar a tomada de decisões na busca de correções de rumos desejados.

Um painel, com indicadores de desempenho bem determinados e ajustados aos objetivos estratégicos possibilitará sustentar os sistemas de apoio a tomada de decisões na gestão das IFES brasileiras.

\subsection{Motivação - Uma análise do contexto e da gestão institucional das IFES}

Alguns dos principais motivos para a execução deste trabalho são os profundos desafios de gestão apresentados ao conjunto das IFES no Brasil, principalmente em virtude das mudanças políticas e socioeconômicas que ocorrem de forma constante em nosso país.

Com esta percepção, fica manifesta a importância de consolidar um conjunto de informações que possam dar conhecimento aos gestores, tanto sobre em que grau está o seu desempenho em relação aos seus objetivos, bem como uma melhor leitura da sua realidade enquanto organização bem como do contexto em que está inserida. A existência deste conjunto de informações é que permitirá viabilizar o aprimoramento do seu processo de tomada de decisões, e consequentemente, produzir um sistema que possa sustentar sua evolução de forma concreta e o mais precisa possível.

No campo da educação, o início deste século tem como característica um forte crescimento na quantidade de vagas ofertadas pelas instituições superiores de ensino, o que por si só, nos indica a necessidade de aprimoramento da gestão das instituições ofertantes. A tabela abaixo fornecida por INEP (2015) permite observar isto relacionando a quantidade de ingressos ocorridos nas instituições de nível superior nos anos do início desta década com os dados do ano final do século passado. 
Tabela 1 - Ingressos na Educação Superior

\begin{tabular}{|c|c|c|c|c|}
\hline Ano & \multicolumn{1}{c}{ Total } & Publica & \% Crescimento & Privada \\
\hline 2000 & 1.035 .850 & 261.114 & & 774.636 \\
\hline 2010 & 2.182 .229 & 475.884 & 82.25 & 1.706 .345 \\
\hline 2011 & 2.346 .695 & 490.680 & 87.92 & 1.856 .015 \\
\hline 2012 & 2.747 .089 & 547.897 & 109.83 & 2.199 .192 \\
\hline 2013 & 2.742 .950 & 531.846 & 103.68 & 2.211 .104 \\
\hline
\end{tabular}

Fonte: INEP (2015)

A figura seguinte, fornecida pelo TCU (2014) revela graficamente os saltos diferenciados que ocorrem na variação orçamentária da educação, onde observamos até $42,14 \%$ de crescimento entre 2010 e 2013 da despesa empenhada.

Figura 1 - Execução orçamentária e financeira da função educação, de 2010 a 2013

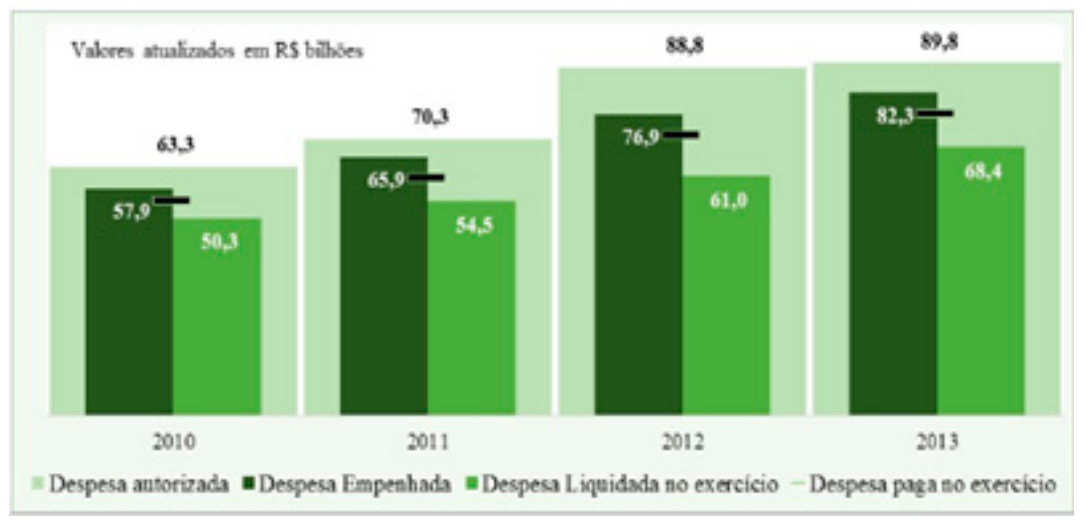

Fonte: TCU - Tribunal de Contas da União

A próxima tabela também apresenta a variação do crescimento dos gastos federais com a educação. Nela se percebe o quanto os recursos para a função educação podem crescer e diminuir em relação a cada ano, considerando período com os últimos 3 anos.

Tabela 2 - Gastos Federais com Educação

\begin{tabular}{|c|c|c|c|c|}
\hline Ano & Recursos & Educação & Relação & Variação \\
\hline 2013 & $1.767 .411 .281 .856,04$ & $74.522 .118 .432,91$ & $4,22 \%$ & \\
\hline 2014 & $2.193 .634 .079 .203,88$ & $91.722 .722 .301,18$ & $4,18 \%$ & $23,08 \%$ \\
\hline 2015 & $2.246 .450 .998 .750,23$ & $94.346 .062 .676,94$ & $4,20 \%$ & $2,86 \%$ \\
\hline
\end{tabular}

Fonte: Portal da Transparência (compilado)

As mudanças e variações também são observadas na tabela abaixo que apresenta os valores destinados ao Ministério da Educação, à Instituição IFSC - Instituto Federal de Santa Catarina, ou à Assistência Estudantil (A.E.) desta instituição a cada ano desde 2004. 
Tabela 3 - Gastos Federais com Educação, uma Instituição e um Programa Específico

\begin{tabular}{|c|c|c|c|c|c|c|}
\hline Ano & MEC & $\%$ & IFSC & $\%$ & A.E. & $\%$ \\
\hline 2004 & $14.892 .599 .998,03$ & & $38.144 .678,10$ & & $217.562,50$ & \\
\hline 2005 & $15.957 .022 .741,83$ & 7,15 & $38.358 .392,79$ & 0,56 & $234.727,49$ & 7,89 \\
\hline 2006 & $19.215 .633 .954,20$ & 20,42 & $57.460 .352,27$ & 49,80 & $335.936,39$ & 43,12 \\
\hline 2007 & $21.134 .152 .546,30$ & 9,98 & $70.954 .277,52$ & 23,48 & $387.708,81$ & 15,41 \\
\hline 2008 & $25.565 .659 .955,99$ & 20,97 & $88.633 .025,60$ & 24,92 & $692.237,18$ & 78,55 \\
\hline 2009 & $31.361 .562 .257,15$ & 22,67 & $131.745 .236,95$ & 48,64 & $1.094 .842,01$ & 58,16 \\
\hline 2010 & $32.254 .125 .219,25$ & 2,85 & $136.816 .169,86$ & 3,85 & $1.352 .408,64$ & 23,53 \\
\hline 2011 & $44.455 .521 .178,79$ & 37,83 & $200.069 .185,47$ & 46,23 & $4.368 .559,56$ & 223,02 \\
\hline 2012 & $51.323 .574 .984,99$ & 15,45 & $237.248 .882,00$ & 18,58 & $6.654 .185,84$ & 52,32 \\
\hline 2013 & $65.152 .892 .241,97$ & 26,95 & $300.083 .045,19$ & 26,48 & $9.071 .696,46$ & 36,33 \\
\hline 2014 & $80.582 .213 .912,65$ & 23,68 & $383.271 .911,93$ & 27,72 & $12.140 .979,36$ & 33,83 \\
\hline 2015 & $85.088 .283 .968,76$ & 5,59 & $408.707 .085,25$ & 6,64 & $11.542 .662,57$ & $-4,93$ \\
\hline 2016 & & & & & $* 7.200 .000,00$ & -37.62 \\
\hline
\end{tabular}

Fonte: Portal da Transparência (Compilado) e * Estimativa DAE (Dir. Assuntos Estudantis) d o IFSC

Com estas informações, fica demonstrado claramente a inconstância e a aleatoriedade na variação dos gastos, acarretando assim dificuldades de gestão desde as mais altas esferas, até as esferas mais inferiores da ação institucional como no caso, os programas de Assistência Econômica ao Estudante.

Além desta situação adversa, em várias áreas da administração pública e principalmente das IFES, são identificadas dificuldades de gestão em decorrência de suporte informacional sobre a realidade das mesmas. Seja por falta de monitoração ou mesmo por falta de definição clara de objetivos.

Observamos, por exemplo, na gestão de pessoas muitas dificuldades. O acórdão 3023 de 2013 do pleno do TCU relata que em estudo realizado em 337 organizações da Administração Pública Federal, com 305 questionários respondidos, relata vários problemas de gestão nesta área:

- $\quad 54 \%$ das organizações declararam não possuir comitê para auxiliar a alta administração nas decisões relativas à gestão de pessoas e, entre as que declararam possuí-lo, apenas 33\% o monitoram regularmente (Questões 17 e 19);

- $\quad 86 \%$ não publicaram diretrizes que contemplem a gestão de riscos relacionados ao capital humano, e 49\% não aprovam plano de auditoria interna que contemple a avaliação periódica desses riscos (como por exemplo greve, falta de competências críticas, perda de pessoas-chave e desperdício de recursos públicos) e a eficácia dos respectivos controles (Questões 10 e 20);

- $\quad$ somente 54\% monitoram regularmente o cumprimento das diretrizes relativas à gestão de pessoas e somente $51 \%$ monitoram regularmente o desempenho da área, atuando quando as metas não são alcançadas (Questões 16 e 21). (TCU, 2013)

Outra situação encontrada pelo TCU, agora no âmbito apenas das Universidades e Institutos Federais e alguns outros órgãos do MEC, é a que foi apresentada em TCU (2014). De acordo com a figura abaixo, fica demonstrado o não atendimento destes planos estratégicos. 
Figura 2: Adoção de práticas relacionadas ao alinhamento estratégico da gestão de pessoas

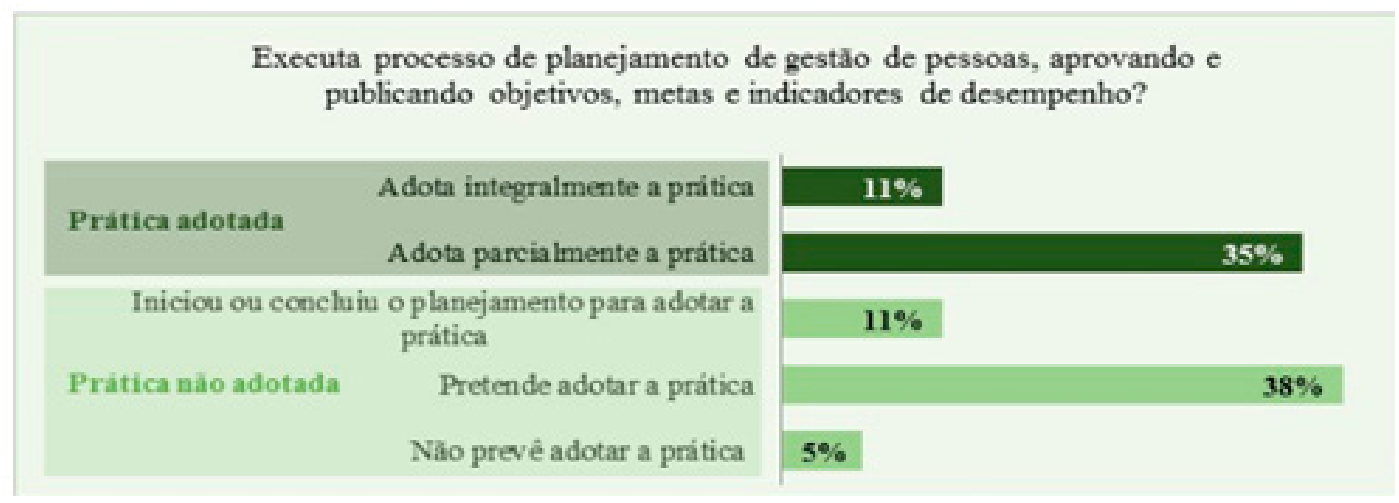

Fonte: TCU - Tribunal de Contas da União (2014)

Igualmente, conforme figura abaixo, vemos que mesmo na área de TI ainda em 2014, apenas $54 \%$ das organizações fazem vínculo de suas ações de TI a indicadores de negócio, através da evolução de seus PDTI's - Planos Diretores de Tecnologia da Informação.

Figura 3 - Evolução dos PDTI's

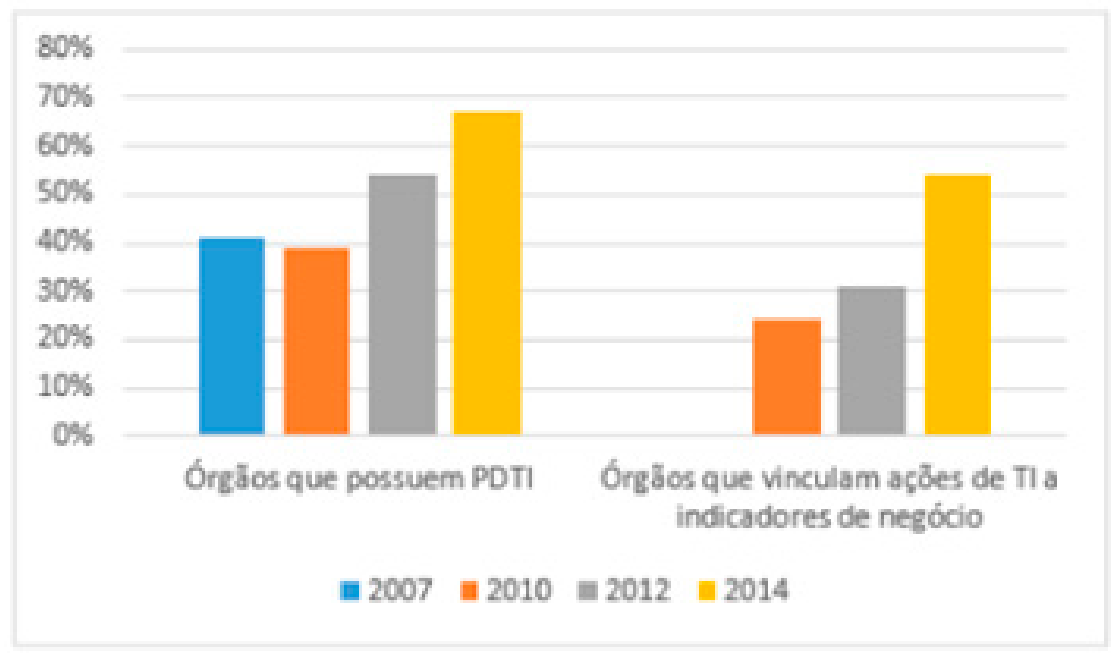

Fonte: Perfil GovTI - (GARCIA;GARCIA, 2016)

A situação coletada e apresentada acima, revela em síntese, um contexto onde existem dificuldades de gestão dado a permanente alteração do quadro em que as instituições estão inseridas. E por outro lado, apresenta uma dificuldade em determinar objetivamente um arcabouço de planejamento onde minimamente se apresentem os objetivos bem determinados, os indicadores de atingimento destes objetivos, bem como indicadores que apresentem a realidade a transformar para se atingir estes objetivos.

Há que se registrar que existem indicadores que o governo federal cobra das IFES, mas a ausência de um conjunto definido e completo é apresentada por Sonnenborn (2004) em seu estudo, quando nos diz, neste caso sobre as instituições privadas (que por si tendem a apresentar uma gestão mais sólida do que as públicas), que: 


\begin{abstract}
"Na gestão de organizações educacionais, devem ser consideradas algumas características especificas que as diferem das demais organizações. Estas características, muitas vezes, impedem que a gestão estratégica destas organizações, quando a possuem, tenha um método definido com objetivos claros e amplamente divulgado para os seus empregados."
\end{abstract}

E segue em frente afirmando que:

"Muitas destas instituições adotam como estratégia de gestão, tão somente
o acompanhamento dos indicadores financeiros tradicionais e o atendimen-
to às exigências legais, mais especificamente as exigências das avaliações
institucionais determinadas pelo Ministério da Educaçâo e Cultura (MEC)"

Esta conclusão corresponde a afirmativa de Silva (2016) que enquanto diretora nas áreas de Gestão de Conhecimento e Planejamento da instituição x, nos diz em entrevista (registrado por e-mail) que:

“...temos uma padronização, no âmbito dos IF's, apenas dos indicadores
obrigatórios do TCU, que compõem o Relatório de Prestação de Contas/Ges-
tão anual. Todos os IF's têm que disponibilizá-los anualmente nos documen-
tos citados. O problema é que grande parte deles não contribuem para uma
análise da efetividade da gestão...”

Além disso é indiscutível a relevância da disponibilidade das informações apropriadas para o administrador no processo decisório, principalmente no momento da tomada de decisão. Sem elas o administrador decidirá as cegas. Esta mesma informação servirá como instrumento de avaliação da qualidade da decisão, tomada por meio da alimentação de um processo de feedback. Ou seja, a correção ou não da decisão tomada influenciará na realidade e esta deve realimentar com segurança as novas leituras da realidade para novo ciclo de tomada de decisões. (PRIMAK, 2008).

\title{
1.2 A Inteligência de Negócios como caminho a seguir.
}

Conforme diz Power (2007), Inteligência Organizacional, ou de Negócio, traduzido do inglês Business Intelligence (BI), é um termo que foi cunhado e popularizado por Howard Dresser do Gartner Group em 1989. Ele descreve um conjunto de conceitos e métodos para melhorar a tomada de decisão de negócios usando sistemas de apoio baseados em fatos (e fatos, quando medidos ao longo do tempo são indicadores).

Se considera então, que dentro de uma instituição, Inteligência Organizacional, constitui-se em um processo, com atividades e ferramentas utilizadas para obter a melhor informação, tendências e comportamentos que possam apoiar a tomada de decisões (PRIMAK, 2008).

Como proposta para a solução deste problema, a Inteligência Organizacional sugere a construção de um grande banco de dados com a responsabilidade de armazenar dados de diversas fontes para futura geração de informações integradas. Ou ainda, com base nos dados extraídos do funcionamento das funções operacionais de uma organização, consolidá-los para seu uso em análises executivas, a partir da reorganização e combinação destes mesmos dados e informações. Este banco de dados é chamado de Data Warehouse (REZENDE; ABREU, 2011).

Para montar este aparato, é necessário então elencar quais seriam as informações desejadas. Estas, em formato de indicadores de desempenho, comporão a base de conhecimento desejada para o sistema ou processo de apoio à tomada de decisões. Serão elas, os requisito de 
informação para a implementação futura de qualquer Sistema de Apoio a Decisão nas IFES. Mas como fazer isto?

\subsection{Definição do problema.}

A carência demonstrada até aqui, reside em indicadores de desempenho que permitam aos gestores, dentro das suas instituições, tomarem as decisões necessárias para o atingimento do planejamento estratégico já existente e que permita avaliar, através do feedback, os resultados obtidos, realimentando o processo decisório.

São reconhecidos alguns indicadores preexistentes, principalmente no âmbito do governo federal. Mas não detectamos na pesquisa a existência de um quadro de indicadores construídos a partir das reais necessidades das IFES.

Sonneborn (2004), em seu estudo sobre as IES privadas, identificou problema semelhante quando nos diz que muitas delas adotam como estratégia de gestão, tão somente o companhamento dos indicadores financeiros tradicionais e o atendimento às exigências legais, mais especificamente as exigências das avaliações institucionais determinadas pelo Ministério da Educação e Cultura (MEC).

Sendo assim, mesmo que os objetivos estratégicos das IFES's possam e devam estar alinhados aos objetivos estratégicos gerais da política de educação do governo, as informações que irão compor o conjunto de conhecimento das instituições, deve nascer das necessidades destas no seu processo de decisão, e em direção aos objetivos definidos em seus próprios planejamentos.

Neste sentido, pesquisando o planejamento institucional já existente nos documentos estratégicos das IFES, no conhecimento dos gestores, e na bibliografia da área, pretendemos identificar os objetivos estratégicos que orientam este grupo de instituições. A partir destes objetivos, desejamos determinar o conjunto de informações, em formato de indicadores, que permitam aos gestores acompanhar a execução e os reflexos das ações gerenciais na realidade da instituição e da comunidade que a cerca.

\subsubsection{Questão da Pesquisa}

Pode, um método baseado em Grounded Theory, identificar os indicadores de desempenho mais importantes para monitorar o grau de consecução dos objetivos estratégicos das IFES e subsidiar suas decisões gerenciais?

\subsubsection{Objetivo}

O objetivo geral do presente trabalho será estabelecer e testar um método de construção de um conjunto definido de indicadores de desempenho estratégico para as IFES.

Os objetivos específicos a serem alcançados são:

- $\quad$ Promover revisão da literatura;

- $\quad$ Propor método de levantamento dos indicadores de desempenho;

- Determinar escopo de testes;

- $\quad$ Promover análise documental do planejamento institucional das IFES selecionadas; 
- Determinar um conjunto de indicadores estratégicos para as IFES selecionadas com base no método;

- $\quad$ Avaliar resultados obtidos.

\section{REVENDO A LITERATURA, CONCEITOS E TÉCNICAS.}

\subsection{Inteligência de Negócio.}

A construção de Indicadores que possibilitem aos gestores de instituições públicas ou privadas decidir sobre as questões, sejam do dia a dia, táticas ou estratégicas, sempre esbarraram na necessidade de compilação de um número muito grande de dados, e na dificuldade de obtenção dos mesmos, tendo em vista que seus repositórios se apresentam de formas diversas, desde folhas de papel, cadernos, livros contábeis, planilhas eletrônicas até sistemas computacionais.

Por outro lado, o desenvolvimento dos bancos de dados, das técnicas de acesso e integração entre várias plataformas, SOA-Arquitetura Orientada a Serviços, e muitas das novas tecnologias, já obtivemos condições de construir, armazenar e acessar, de forma organizada e inteligente, os dados e informações sobre a vida da organização.

Apesar de não existir um conceito petrificado para esta área de domínio de conhecimento, bem como, não existir alguma organização ou instituição internacional reconhecida e preocupada com normatização em B.I. - Business Intelligence (ou Inteligência Empresarial), a literatura tende atualmente a convergir para uma definição pacífica.

Já vimos anteriormente que o termo Business Intelligence ou Inteligência Empresarial surgiu na década de 80 no Gartner Group e faz referência ao processo inteligente de coleta, organização, análise, compartilhamento e monitoramento de dados contidos em um Data Warehouse/Data Mart, gerando informações para o suporte à tomada de decisões no ambiente de negócio.

Inteligência Empresarial, ou de Negócio, segundo Cunha (2012), também é o processo que uma organização pode utilizar para converter todos os seus recursos em conhecimento, dando as informações certas às pessoas certas e no momento certo; produzindo grandes quantidades de informação, levando ao desenvolvimento de novas oportunidades para a organização. Em outras palavras, é o processo de coleta, organização, análise, compartilhamento e monitoramento de informações que oferecem suporte a gestão e o sucesso dos negócios.

Por outro lado, segundo Ferreira, Cassiolato e Gonzalez (2009), um indicador seria:

\footnotetext{
"uma medida, de ordem quantitativa ou qualitativa, dotada de significado particular e utilizada para organizar e captar as informações relevantes dos elementos que compõem o objeto da observação. É um recurso metodológico que informa empiricamente sobre a evolução do aspecto observado."
}

Considerando este conceito de indicadores e o entendimento apresentado do que significa inteligência empresarial, deduzimos que a construção de indicadores para qualquer atividade, inclusive a educação, pode ser considerada uma ação de inteligência empresarial, uma vez que indicadores são métricas obtidas no dia a dia que, em sendo observados ao longo do tempo, podem demonstrar comportamentos, tendências, etc... Sendo assim, constituem-se em importantes elementos de suporte à tomada de decisão. Ou seja, são informações, que derivadas dos dados dos sistemas transacionais, se transformam em conhecimento (XXXXXXX, 9999) 
2.2 Sistemas de Suporte ou Apoio a Tomada de Decisões.

As organizações necessitam cada vez mais dos sistemas de informação (SI) e da tecnologia da informação (TI) para apoiar a tomada de decisões. (REZENDE, 2011)

Mas os Sistemas de Suporte a Decisão (SSD ou DSS), conforme Guerreiro (2007), não são sistemas de produção. São sistemas geradores de conhecimento, onde conhecimento seria a informação trabalhada, que possibilita auxiliar o gestor a fazer a melhor opção em tempo útil. E não podem substituir as pessoas no processo de decisão porque não têm a capacidade dos humanos de serem criativos, imaginativos, ou intuitivos.

Primak (2008, p.66) nos diz que em suma, a estratégia para elaboração de um Sistema de Apoio a Decisões seria:

\begin{abstract}
"Inicialmente é necessário definir quais dados, gerados nos sistemas transacionais, serão armazenados no data warehouse, para depois partir para a modelagem dimensional e a criação física do modelo no qual as especificidades do Sistema Gerenciador de Banco de Dados (SGBD) e da ferramenta OLAP escolhidos serão considerados para otimizar as consultas futuras."
\end{abstract}

Data WareHouse, modelagem dimensional e ferramentas OLAP, são conceitos embutidos nas técnicas de Inteligência de Negócios quando construindo Sistemas de Apoio a Tomada de Decisão. Serão estudados em momento oportuno. O importante é o destaque dado a necessidade de definir os dados, as informações, o conhecimento, etc... utilizado e desejado.

\title{
2.3 Importância dos indicadores. Requisitos de Informação e de negócio.
}

Conforme nos diz Sonnenborn (2004),

"Criar medidas e instrumentos de desempenho padronizados sempre foi um desafio para a humanidade. Todas as organizações, independente do segmento empresarial em que atuam, precisam de medidas confíveis e indicadores que permitam mensurar o desempenho de suas atividades."

Ou Slack, Chambers e Johnston (2009 apud OLIVEIRA, 2012),

"Medir o desempenho é quantificar a ação. Medição significa quantificação, e o desempenho é presumido como derivado das ações administrativas. Uma medida de desempenho é imprescindivel para verificar se uma ação é boa, ruim ou indiferente. Sem mensurar é impossivel exercer o controle contínuo sobre um processo.."

Assim, com esta perspectiva de importância, tendo como orientação a Inteligência de Negócios e a possível e necessária construção de um Sistema de Apoio a Tomada de Decisão, necessitamos definir, quais seriam os requisitos de informação, para este sistema. E para isto precisamos determinar um método.

\section{GROUNDED THEORY COMO MÉTODO A APLICAR NO LEVANTAMENTO.}

\subsection{Oque é?}

Apenas para situar o desenvolvimento histórico do método, a contribuição de BANDEIRA-DE-MELLO e CUNHA (2003) apresenta o seguinte:

"O método da Grounded Theory surgiu em Glaser e Strauss (1967). Teve seu desenvolvimento em Glaser (1978) e Strauss (1987), com contribuição 
substancial de Strauss e Corbin (1998). A Grounded Theory é, geralmente, apresentada como uma abordagem de pesquisa qualitativa. No entanto, há duas linhas divergentes quanto ao método. Uma delas é defendida por Glaser (1992) e dá ênfase a característica emergente do método e aos processos indutivos desenvolvidos pioneiramente pelo Departamento de Sociologia da Universidade de Columbia nos anos 50 e 60. A outra linha - considerada por Glaser a antitese da Grounded Theory, pois, segundo o autor, permite a influência de preconcepções do pesquisador - foi desenvolvida por Strauss (1987) e consolidada em Strauss e Corbin (1998), com primeira edição em 1990, livro que tornou o método, suas técnicas e procedimentos populares na comunidade acadêmica."

Grounded Theory é um método científico onde a teoria surge dos dados analisados, ou seja, é uma teoria fundamentada em uma análise sistemática de dados. (BANDEIRA-DE-MELLO;CUNHA, 2003).

Para Strauss e Corbin (1998 apud BANDEIRA-DE-MELLO;CUNHA, 2003), a teoria formulada pelo método deve apresentar as seguintes características: a) coerência entre os dados e resultados; b) compreensão pelo envolvidos; c) generalização suficiente para que variações da ocorrência do fenômeno sejam consideradas; e d) controle na previsão das ações dos envolvidos. Ademais, deve ser coerente com a realidade da área especificada para o estudo e, como consequência, fornecer sentido para que seja compreendida pelos sujeitos envolvidos e por outros pesquisadores.

Os processos que compõem a Grounded Theory são basicamente, conforme GARCIA E GARCIA (2016), os seguintes:

- $\quad$ Codificação Aberta: etapa em que o pesquisador varre o material coletado e busca extrair conceitos, categorias e suas propriedades e dimensões;

- $\quad$ Codificação Axial: nesta etapa ocorre o processo de relacionar categorias entre si e entre as propriedades e dimensões. Através destes relacionamentos é possível traçar proposições acerca do fenômeno estudado;

- $\quad$ Codificação Seletiva: etapa em que o pesquisador identifica a categoria central do fenômeno e realiza o refinamento da teoria que emerge dos dados.

A figura abaixo ilustra a sequência destes passos.

Figura 4 - Ilustração do Processo de Coleta e Análise

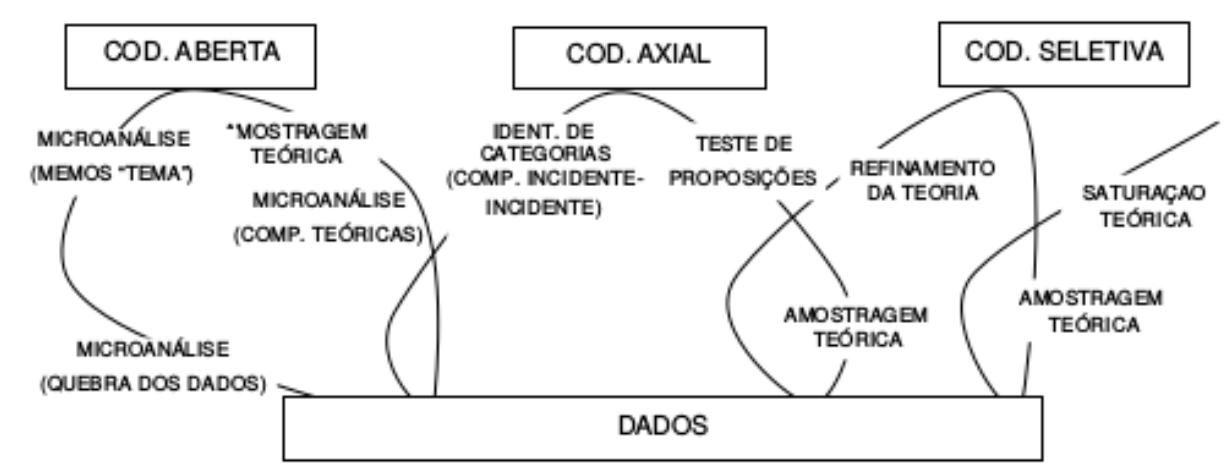

Fonte: Bandeira-de-Mello e Cunha (2003) 


\subsection{Porque Usar?}

O objetivo final não é fazer "uma teoria surgir dos dados" como preconiza a Grounded Theory. Tentamos identificar um conjunto de informações que poderão ser organizadas em trabalhos futuros como um conjunto de objetivos estratégicos e os possíveis indicadores que sustentariam um Sistema de Apoio a Tomada de Decisão.

Por outro lado, observamos que os passos adotados pela Grounded Theory e definidos em seu método, tem condições de auxiliar como método para a busca dos objetivos acima. Desta forma, será usada como ferramenta fundamental para analisar o planejamento estratégico das instituições em busca da extração não de uma teoria, mas de um conjunto de informações estruturadas que se tornariam o conhecimento desejado.

\section{ANÁLISE DOCUMENTAL APLICANDO GROUNDED THEORY.}

De forma a tentar atingir o objetivo de testar o método da Grounded Theory na análise documental dos planos estratégicos das IFES e deles extrair um painel de indicadores de desempenho, vamos selecionar uma pequena amostra de instituições para este fim.

Estas instituições serão um Instituto Federal e uma Universidade Federal. Um deles da região sul e um deles da região nordeste.

[Tendo em vista que as instituições escolhidas são aquela onde o autor exerce suas atividades profissionais e aquela onde desenvolve seu mestrado, ambas serão omitidas aqui e reveladas posteriormente em caso de aceitação do trabalho.]

Bandeira-de-Mello e Cunha (2003) apresentam em seu trabalho, os elementos a identificar e construir, conforme uma ferramenta de mercado, usando Grounded Theory. Estes elementos são apresentados na tabela abaixo e serão os elementos a usar, com as adaptações necessárias, no trabalho de construção do nosso Painel de Indicadores a partir da análise documental. 
Tabela 4 - Principais elementos do ATLAS/ti

\begin{tabular}{|c|c|}
\hline Elemento & Descrição \\
\hline $\begin{array}{l}\text { Unidade hermenêutica } \\
\text { (Hermeneutic unit) }\end{array}$ & Reúne todos os dados e os demais elementos. \\
\hline $\begin{array}{l}\text { Documentos primários } \\
\text { (Primary documents) }\end{array}$ & $\begin{array}{l}\text { São os dados primários coletados. Em geral, são transcrições de entrevistas e notas } \\
\text { de campo e de checagem. São denominados de Px, onde x é o número de ordem. }\end{array}$ \\
\hline $\begin{array}{l}\text { Citações } \\
\text { (Quotes) }\end{array}$ & $\begin{array}{l}\text { Trechos relevantes das entrevistas que geralmente estão ligados a um código. Sua } \\
\text { referência é formada pelo número do documento primário onde está localizada, se- } \\
\text { guido do seu número de ordem dentro do documento. Também constam da referência } \\
\text { as linhas inicial e final. }\end{array}$ \\
\hline $\begin{array}{l}\text { Códigos } \\
\text { (Codes) }\end{array}$ & $\begin{array}{l}\text { São os conceitos gerados pelas interpretações do pesquisador. Podem estar associa- } \\
\text { dos a uma citação ou a outros códigos. São indexados pelo nome. Apresentam dois } \\
\text { números na referência. O primeiro se refere ao número de citações ligadas a ele; e o } \\
\text { segundo, ao número de códigos. Os dois números representam, respectivamente, o } \\
\text { grau de fundamentação (groundedness) e o de densidade (density) do código. }\end{array}$ \\
\hline $\begin{array}{l}\text { Notas de análise } \\
\text { (Memos) }\end{array}$ & $\begin{array}{l}\text { Descrevem o histórico da interpretação do pesquisador e os resultados das codifica- } \\
\text { ções até a elaboração final da teoria. }\end{array}$ \\
\hline $\begin{array}{l}\text { Esquemas } \\
\text { (Netview) }\end{array}$ & $\begin{array}{l}\text { São os elementos mais poderosos para exposição da teoria. São representações gráfi- } \\
\text { cas das associações entre os códigos (categorias e subcategorias). O tipo das relações } \\
\text { entre os códigos é representado por símbolos. }\end{array}$ \\
\hline $\begin{array}{l}\text { Comentário } \\
\text { (Comment) }\end{array}$ & $\begin{array}{l}\text { Todos os elementos podem e devem ser comentados, principalmente os códigos, } \\
\text { fornecendo informações sobre seu significado. }\end{array}$ \\
\hline
\end{tabular}

Fonte: Bandeira-de-Mello e Cunha (2003)

\section{PAINEL DE INDICADORES RESULTANTE.}

Na sequência, apesar de não ser o objetivo deste estudo, apresentaremos o conjunto de indicadores que foram extraídos dos PDI's submetidos ao método adaptado da Grounded Theory e sendo eles o resultado da extração feita.

Inicialmente, é necessário clarear que qualquer um dos indicadores elencados, possui uma dimensão temporal, ou seja, todos eles correspondem a uma métrica observada ao longo do tempo. No caso das IFES, esta dimensão tende a ser o semestre dado que a maioria dos cursos acompanha este período de tempo. Mas nada impede que as métricas sejam auferidas em outra periodicidade e compostas em categorias como ano, semestre, trimestre e mês, umas compostas pelas outras.

Em segundo lugar, a maioria dos indicadores em uma IFES se reporta a mais algumas dimensões como o curso, a modalidade do curso, o nível, o campus, o departamento ou centro, o município, etc... 
Os indicadores são instrumentos para medir atingimento de objetivos estratégicos. Não é preocupação do trabalho definir qual indicador melhor atende a qual objetivo. Apenas determinar se o método pode fornecê-los.

Em ambos os casos não mencionaremos estas dimensões no quadro abaixo onde listamos os indicadores resultantes.

Tabela 5 - Painel resumido dos indicadores de desempenho coletados

\begin{tabular}{|c|c|c|}
\hline Indicador & Descrição & Dimensões \\
\hline Alunos & $\begin{array}{l}\text { Quantidades de alunos cursando, } \\
\text { trancados, jubilados, formados }\end{array}$ & \\
\hline Apoio Presencial & $\begin{array}{l}\text { Quantidade de polos de apoio } \\
\text { presencial }\end{array}$ & Cidade \\
\hline Assistência Estudantil & $\begin{array}{l}\text { Quantidade de benefícios concedi- } \\
\text { dos a estudantes }\end{array}$ & Tipo da bolsa \\
\hline Assistência Social & $\begin{array}{l}\text { Quantidade de acionamentos de } \\
\text { Assistente Social para atendimento } \\
\text { a estudante }\end{array}$ & \\
\hline Atendimento Psicológico & $\begin{array}{l}\text { Quantidade de acionamentos de } \\
\text { psicologo para atendimento a } \\
\text { estudante }\end{array}$ & Motivação \\
\hline Aulas & Quantidade de aulas ocorridas & $\begin{array}{l}\text { Disciplina; Eixo Temático; área de } \\
\text { Conhecimento }\end{array}$ \\
\hline Beneficiários & $\begin{array}{l}\text { Quantidades de beneficiários por } \\
\text { ações afirmativas por idade, cor, } \\
\text { etc... }\end{array}$ & Programa \\
\hline Capacitação & Quantidades de capacitação & $\begin{array}{l}\text { Tipo }\{\text { TAE,Docente }\} \text {; Pais; Nível } \\
\text { \{graduação, pós graduação, técni- } \\
\text { co, FIC,... }\end{array}$ \\
\hline Contratação & $\begin{array}{l}\text { Quantidades de contratações de } \\
\text { docentes e técnicos }\end{array}$ & Tipo $\{$ TAE, Docente $\}$ \\
\hline Cooperação & $\begin{array}{l}\text { Quantidade de acordos de coopera- } \\
\text { ção firmados e em andamento. }\end{array}$ & Instituição; País. \\
\hline Corpo Docente & $\begin{array}{l}\text { Quantidade de docentes por titula- } \\
\text { ção, regime, vínculo, faixa etária, } \\
\text { etc... }\end{array}$ & \\
\hline Corpo Técnico & $\begin{array}{l}\text { Quantidade de TAES por titula- } \\
\text { ção, regime, vínculo, classe, faixa } \\
\text { etária, etc... }\end{array}$ & \\
\hline Cursos & Cursos ofertados pela instituição & $\begin{array}{l}\text { Classificação Cpqd; } \\
\text { Nível \{Graduação, Pós Stricto } \\
\text { Sensu Mestrado, Pós Stricto Sensu } \\
\text { Doutorado, Pós Latu Sensu, ... }\} \text {; } \\
\text { Conceito; \%aDistância; \%Exten- } \\
\text { são; \%ExtensãoSocial }\end{array}$ \\
\hline Desempenho & Índice de desempenho médio & $\begin{array}{l}\text { Aluno; Característica sócio econô- } \\
\text { mica do aluno; Cota de ingresso }\end{array}$ \\
\hline Estágio & $\begin{array}{l}\text { Quantidade de ofertas e preenchi- } \\
\text { mento de vagas }\end{array}$ & Empresa; Região; Setor; Bolsa \\
\hline
\end{tabular}




\begin{tabular}{|c|c|c|}
\hline Evasão & Quantidade de alunos que evadem & $\begin{array}{l}\text { Nível de Vulnerabilidade; Cota de } \\
\text { ingresso }\end{array}$ \\
\hline $\begin{array}{l}\text { Extensão. } \\
\text { ações }\end{array}$ & Ações de extensão realizadas & Tipo \\
\hline Intercambismo & $\begin{array}{l}\text { Quantidade de alunos em intercâm- } \\
\text { bio }\end{array}$ & Tipo \\
\hline Laboratório & $\begin{array}{l}\text { Quantidade numérica e em } \mathrm{m} 2 \mathrm{de} \\
\text { laboratórios }\end{array}$ & Prédio \\
\hline Material Divulgação & $\begin{array}{l}\text { Quantidade de material de divulga- } \\
\text { ção elaborado }\end{array}$ & $\begin{array}{l}\text { Tipo \{Gráfico, audiovisual,...\}; } \\
\text { Sub-tipo \{panfleto, caderno, } \\
\text { flyer,...\}; Idioma }\end{array}$ \\
\hline Oferta & $\begin{array}{l}\text { Vagas novas ofertadas pela institui- } \\
\text { ção independentemente de preen- } \\
\text { chimento }\end{array}$ & \\
\hline Patentes & $\begin{array}{l}\text { Quantidade de patentes requeridas } \\
\text { e aprovadas }\end{array}$ & \\
\hline $\begin{array}{l}\text { Pedidos de Propriedade Intelec- } \\
\text { tual }\end{array}$ & $\begin{array}{l}\text { Quantidade de Pedidos de pro- } \\
\text { priedade intelectual solicitada e } \\
\text { concedida }\end{array}$ & \\
\hline Pontos de função & $\begin{array}{l}\text { Quantidade de pontos de função } \\
\text { previstos e executados }\end{array}$ & $\begin{array}{l}\text { Desenvolvedor }\{\text { interno, externo } \\
\text { proprietário, externo livre, ...\}; } \\
\text { Sistema; Área gestora }\end{array}$ \\
\hline Produção Científica & $\begin{array}{l}\text { Quantidades de publicações, cita- } \\
\text { ções, índice h }\end{array}$ & \\
\hline Segurança & $\begin{array}{l}\text { Ocorrências relacionadas a segu- } \\
\text { rança do patrimônio e das pessoas }\end{array}$ & $\begin{array}{l}\text { Tipo }\{\text { Roubo extramuro, Roubo } \\
\text { intramuros, Furto, Arrombamento }\}\end{array}$ \\
\hline
\end{tabular}

Fonte: Levantamento efetuado pelos autores

\section{CONCLUINDO E AVALIANDO OS RESULTADOS.}

A aplicação dos passos do método foi adequada ao objetivo. Não apenas atingimos a meta definida com sucesso, permitindo a construção do esboço de um painel de indicadores apresentado acima, como também, em função de sua aplicação, se revelaram mais duas qualidades possíveis de desenvolver, quais sejam:

1. A priorização na implementação dos indicadores para análise da situação e apoio ao processo decisório pode se dar por dois fatores inerentes ao método, que são a determinação do grau de fundamentação e do grau de densidade dos códigos dos elementos que se constituem os indicadores.

2. Os relacionamentos dos códigos dos elementos do tipo objetivo, relacionados com os códigos dos elementos do tipo indicadores, pode predefinir, quando localizados, as relações entre eles. Assim, o relacionamento em um mapa de BSC-Balanced Scorecard, GQM-Goal, Question, Metric, ou outro qualquer método de relacionamento entre objetivos estratégicos e indicadores de desempenho já brotaria, pelo menos em boa parte, do levantamento quando aplicado o método.

\section{Outras considerações:}

Percebe-se que indicadores não estão na cultura das instituições, pelo menos das duas utilizadas na amostra. Não há clareza na apresentação de quais são os indicadores e menos de qual são as relações entre eles e os objetivos. Isto fortalece a importância do método. 
Em ambos os planejamentos, embora muito mais em um do que em outro, existe a tentativa de qualificar os objetivos por área de atuação da instituição. Isto prejudica a identificação das relevâncias e produz algumas redundâncias.

Apesar de ser qualitativa a resposta obtida pelo método, o aspecto quantitativo se revela na intensidade das relações, como constatado no item 1 acima.

Tendo em vista que não é objetivo deste trabalho analisar o conteúdo do resultado alcançado pelo método, ou seja, cada indicador do resultado, mas sim a possibilidade de encontrá-los, esta análise poderá ser o objetivo de um estudo posterior.

Em suma, concluímos que é indicado usar Grounded Theory para o objetivo definido.

\section{REFERÊNCIAS.}

BANDEIRA-DE-MELLO R.; Cunha C.J.C.A. Operacionalizando o método da grounded theory nas pesquisas em estratégia. Artigo 2003. Disponível em $<$ www.anpad.org.br/diversos/trabalhos/3Es/3es_2003/2003_3ES39.pdf>. Acesso em: 18 jul. 2016

CUNHA, Renato. O Sucesso da Inteligência Empresarial. Projetos e Ti, www, p.1-1, 5 jul. 2012. Disponível em: <http://projetoseti.com.br/o-sucesso-da-inteligencia-empresarial-bi/>. Acesso em: 25 jul. 2016.

FERREIRA, H.; CASSIOLATO, M.; GONZALEZ, R.. Uma Experiência de Desenvolvimento Metodológico para Avaliação de Programas: O Modelo Lógico do Programa Segundo Tempo. Texto para Publicação-1369. Rio de Janeiro: IPEA, 2009 - ISSN 1415-4765. Disponível em $<$ http://www.lume.ufrgs.br/handle/123456789/136?show=full $>$. Acesso em 26 de julho de 2016.

GARCIA, Plinio A.; GARCIA, Vinícius C.. Aplicando Grounded Theory para compreender as dificuldades de Planejamento de TI em Órgãos Federais. Anais do IX SBSI, Florianópolis, p.24-26, 2016. Anual.

GUERREIRO, João. História dos Sistemas de Suporte à Decisão. Mestrado de Sistemas Integrados de Apoio à Decisão, ISCTE-Instituto Universitário de Lisboa, 2007. Disponível (resumo) em: $<$ http://guerreirojrpm.wordpress.com/2007/10/18/historia-dos-sistemas-de-suporte-a-decisao>.

INEP-Instituto Nacional de Estudos e Pesquisas Educacionais Anísio Teixeira. Resumo Técnico - Censo da Educação Superior 2013. Brasilia, 2015.

OLIVEIRA, Alexandre de. Proposta de um Sistema de Indicadores de Desempenho para Instituições de Ensino Superior na Perspectiva do Corpo Discente. Dissertação (Mestrado)-Universidade Estadual Paulista. Faculdade de Engenharia de Bauru. Bauru, 2012.

POWER, D.J. A Brief History of Decision Support Systems.DSSResources.COM, World Wide Web, http://DSSResources.COM/history/dsshistory.html, version 4.0, March 10, 2007.

PRIMAK, F. V. da S. Decisões com B.I. (Business Intelligence). Rio de Janeiro: Ed. Ciência Moderna Ltda., 2008. ISBN 9788573937145.

REZENDE, D. A. Rezende. Planejamento de sistemas de informação e informática: guia prático para planejar a tecnologia da informação integrada ao planejamento estratégico das organizações. 4a. Edição, Editora Atlas, 2011. ISBN 9788522461229. 
REZENDE, D. A.; ABREU, A. F. de. Tecnologia da Informação Aplicada a Sistemas de Informação Empresariais. 9a. Edição. São Paulo: Editora Atlas Ltda., 2011. ISBN 978-85-224 75483

SILVA, S. P. F. Entrevista. 2016. E-mail.

SONNEBORN, M. J. Desenvolvimento de um modelo de apoio à gestão para uma instituição de educação superior baseado em indicadores de desempenho. Dissertação - Universidade Federal do Rio Grande do Sul, Lume-Repositório Digital, 2004. Disponível em: <http://www. lume.ufrgs.br/bitstream/handle/10183/5856/000521345.pdf?sequence=1>.

TCU-TRIBUNAL DE CONTAS DA UNIÃO. Acórdão 3023/2013. 2013. Disponível em: $<$ http:// www.lexml.gov.br/urn/urn:lex:br:tribunal.contas.uniao;camara.2:acordao:2013-05- 28;3023>.

TCU-TRIBUNAL DE CONTAS DA UNIÃO. Relatório de Levantamento - TC020.808/2014-3. 2014. www. Disponível em: <http://www.tcu.gov.br/consultas/juris/docs/judoc/acord/20150320/ ac_0528_09_15_p.doc>. 